\title{
2006 APSA Teaching and Learning Conference Track Summaries
}

\section{Internationalizing the Curriculum Track Summary: Realizing the Global Impera- tive in Political Science}

\author{
-Gordon Babst, \\ Chapman University \\ -Denise DeGarmo, \\ SIU Edwardsville \\ -Chris Harth, \\ Global Studies Foundation \\ -Bob Reinalda, \\ Radboud University Nijmegen and epsNet
}

\begin{abstract}
$\mathrm{A}_{\mathrm{t}}^{\mathrm{s}}$ technological advances continue to shrink the effects of distance and increase the connectedness and dynamism of the international system, analysts and educators alike face a growing challenge to adapt to these changing circumstances and the concomitant global issues such as terrorism, trade, investment, environmental catastrophes, climate change, and potential pandemics. Shifting local and global contexts and thickening webs of interaction generate pressures to modify perceptions and practices and make internationalization imperative. The discipline of political science should come to terms with the emergent reality of globalization as soon as possible. While rhetorical support for international education may be strong, as Chris Harth (Global Studies Foundation) pointed out, tremendous opportunities exist for greater internationalization in political science and for substantive improvements in how we educate our students about the world.

As discovered in the recent APSA Teaching and Learning Conference, numerous teaching and learning tools are available and already in use to help internationalize education. Led by Steven Lamy (University of Southern California), nearly 30 educators, researchers, administrators, and practitioners at the Conference wrestled with the challenge to internationalize the discipline of political science. Three days of presentations and discussions provided multiple examples of successful efforts in and out of classrooms at all types of institutions and concluded with recommendations to APSA for taking seriously the global imperative and for better preparing young citizens for the global challenges and opportunities ahead.

Within the classroom, educators can
\end{abstract}

The 3rd Annual APSA Conference on Teaching and Learning in Political
Science hosted over 300 participants in lively discussions of trends,
techniques, and models in teaching in political science. Held in downtown
Washington, D.C. on February 18-20, the Conference was organized as a
workshop-based forum to develop models of teaching and learning as well as
to discuss broad themes affecting political science education today. Joining the
discussion, APSA President Ira Katznelson (Columbia University) and keynote
speaker Thomas E. Cronin (Colorado College) shared their thoughts on teaching
and learning in the discipline. For a full list of participants and more information
on the 2006 Conference, visit www.apsanet.org/section_236.cfm. For
information on the 2007 Conference, contact teaching@apsanet.org.

use a variety of methods to increase student awareness and engagement. Linda Racioppi and Colleen Tremonte (both of Michigan State University), for instance, argued that using interdisciplinary sources in process-oriented pedagogies, such as linking films and literature to texts, can increase understanding of complex themes in international relations. Henrik Schatzinger (University of Georgia), in turn, showed that a comparative approach to the study of U.S. government can both enrich students' understanding of the American system and raise awareness of other countries and systems. Denise DeGarmo (Southern Illinois University, Edwardsville) also demonstrated that virtual simulations and role-playing activities, particularly participation in the ICONS Project, can promote and enhance student engagement in the learning process and help motivate resistant learners, even those with minimal prior exposure to international topics.

The world can be brought into the classroom through other methods as well. Vickie Langohr (College of the Holy Cross) revealed how the use of international newspapers, for example, which are readily available on the Internet, not only can help students better understand other regions, but also can improve their appreciation for media biases and help them see the world from multiple perspectives. Arguing for better collaboration between professional political science organizations, like APSA and epsNET, Bob Reinalda (Radboud University Nijmegen) and Gabriela Gregušová (Comenius University) highlighted the potential advantages for both information flows and international educational opportunities. Institutional collaboration also can bear fruit. Kathleen Claussen (Indiana University) made the case that by providing a shared virtual classroom experience for students and faculty in different parts of the world, interactive international videoconferencing can allow for greater self-discovery, broader perspectives, and heightened awareness of pressing international issues.

Travel abroad for study, internships, work, or service also offers an outstanding opportunity for students and faculty to expand their views, to increase their international awareness, and to have formative experiences that last a lifetime and that can be shared with others. Numerous models of successful travel programs exist, with several features described by participants. Edward Declair (Lynchburg College), for instance, identified key components of international experiential learning, including using multiple mediums for various forms of learning and increasing incentives for faculty participation. In his presentation on the connections between coursework and travel courses, Gordon Babst (Chapman University) argued for grounding pre-departure preparation in political science and other social sciences in order to provide the strongest foundation for successful programs. Finally, Michael Shafer (Rutgers University) made the case for the potentially transformative role of employing a "pedagogy of discovery" and providing hands-on, learning opportunities for young people to work through vexing socio-political issues in conflict-torn areas, such as the former Yugoslavia.

In short, all of the papers underlined the need to increase internationalization and presented opportunities and practical instruments to help the discipline of political science shift to more global perspectives and practices. These suggestions can be used in a variety of institutions, including community colleges, liberal arts colleges, and comprehensive universities, as well as in secondary schools, especially with the Advanced Placement 
curriculum, as Michael Morris (Clemson University) noted. Unfortunately, political science appears to be losing ground as other disciplines move forward with internationalization. While there is no one approach to internationalization, the imperative to update our curriculum is clear. The future leadership role of the discipline is at stake, to say nothing of the preparedness of our students for the 21 st century. Regardless of institution type, faculty and administrators can and should place a higher priority on expanding both the quantity and the quality of internationalization efforts and offering their students greater exposure to and knowledge about our world. Wherever possible, including in continued venues like its Teaching and Learning Conference, APSA should support such efforts within and across the discipline and set an example for others to follow.

\section{Diversity and Inequality Track Summary}

\section{—Amy Cabrera Rasmussen, Chapman University —Reilly Hirst, \\ Portland State University -Anas Malik, Xavier University -Ange-Marie Hancock, Yale University}

$\mathrm{D}_{\mathrm{s}}^{\mathrm{u}}$ uring the Cold War, whistle-blowers and dissenters were threatened and penalized; they lost jobs, faced social and governmental harassment, and often lived thankless and persecuted lives. It was never entirely clear where the speech boundaries lay, or when one might get sanctioned. Today, the "War on Terror" is becoming a hegemonic framework, the Patriot Act has been made permanent, and there are ongoing revelations about increased surveillance in the United States. Along with these developments, there are increasing efforts to punish academics for expressing contentious views. At a minimum, teaching topics that disrupt the comfort zone can be emotionally draining and may produce some negative reactions in the classroom. Under such pressures, self-censorship can be a natural consequence. Yet open democratic deliberation, well-rounded education, and intellectual freedom are prerequisites for best serving our world.

The APSA TLC Diversity and Inequality track provided a civic forum for engagement and deliberation on this question. Civic forums have the potential to provide solidarity, combat debilitating isolation, and promote policy critiques and alternatives. As such, they can reduce perceived barriers to successful challenges and change. This can be troubling to those with vested interests in some status quo. Track participants agreed that alternative and minority positions are under siege in many contexts and examined strategic response to palpably hostile environments in disciplinary, institutional, and classroom contexts.

As a group, we agreed that our conference track provided a welcome and muchneeded space for both the presentation of research and the discussion of pedagogical issues concerning diversity and inequality. Many felt that APSA as an organization might usefully boost its efforts in this area through the construction of additional sites of solidarity and inspiration, integrating these issues into a broader disciplinary discussion including a greater number of our fellow political scientists. Likewise, many participants voiced the need for political science as a discipline to do more to enhance the link between such research and disciplinary-based pedagogical training. Efforts should be made as a discipline to tap into longstanding intellectual traditions, foster a safe environment where all topics might be discussed, and recognize how newly resuscitated debates about academic freedom disproportionately affect non-traditional faculty and those who teach topics regarding race, ethnicity, gender, sexuality, and nation. Last, a consensus emerged regarding the need for political science to improve textbook offerings for introductory U.S. politics courses. Track participants' anecdotal observations that current U.S. politics textbooks contain systematic inadequacies that hinder instructors' ability to address diversity and inequality were confirmed by systematic investigation (Travis et al.).

Participants on our track came from large public universities, small liberal arts or religiously affiliated institutions, and many places in between. Our discussion of diversity and inequality thus reflected these varied origins, and made evident the need for a diversity of innovative teaching strategies taking account of these varied sites, with their concomitant institutional goals and classroom compositions. Yet, some common needs also surfaced: the need for both the core and broader curriculum of the university to support diversity and equality, as well as the necessity of institutional support of vulnerable faculty, as teaching controversial topics like race and gender becomes equated with bias and threatens to seriously impact the teaching of diversity and inequality in the classroom (Sampaio). To protect future tenure and promotion, consensus emerged that non-traditional faculty specifically must be careful to balance their classes explicitly based on race and gender with other courses, invest in honing pedagogical skills, and develop better tools of assessment: producing one's own evaluation forms, doing pre- and post-surveys about class content, getting colleagues to peer review and write supportive letters, as well as push for the ability to reply to falsities in one's evaluations.

As in many tracks, classroom engagement was a topic of considerable concern Teaching methods were highlighted as key. Those who taught with an eye to diversity in the classroom repeatedly stressed the more difficult position of those who teach standing in the position of vulnerability where students are encouraged and pushed into the discomfort zone. In that zone, there is sensitive and engaged response from faculty. This tension between fierce initial response and loving application of wisdom once confusion or discomfort has set in was identified as a critical window of opportunity for innovative turns in supporting students. Admittedly, such turns are emotionally and energetically challenging.

The Diversity and Inequality Track represents one form of additional support to accomplish such teaching. Track presenters enumerated a bevy of strategies to assist in staying open to the radical vulnerability created in the space between confrontation with new perspectives and encouragement. The Socratic Method (Haddad) and cooperative inquiry (Hirst) push students beyond their own perspectives and place them on an equal footing. Cooperative inquiry was in fact the primary method of the track itself, which served as a crossroads for the interrogation of Whiteness (Mohan), turning student ethnic diversity on its ear (Judd), curricular changes to enhance Latino student retention (Huerta), and engendering trust and growth through technology when the teacher, identified as Other, is viewed with suspicion (Malik).

The Diversity and Inequality track was an energizing and renewing experience for everyone, and more so for those who felt isolated, marginalized, and at risk. A clear strategy that emerged in this context was to draw strength from our group members, and to translate our camaraderie into ongoing mutual support. Track participants departed convinced of the necessity of this track at future TLCs, both for their ongoing intellectual preservation and that of their colleagues who remain isolated across the discipline. 


\section{Teaching Research Methods Track Summary}

\author{
-Amy Brandon, \\ University of Houston \\ -Mitchell Brown, \\ American University \\ -Christopher Lawrence, \\ Saint Louis University \\ - Jennifer Van Heerde, \\ University College London
}

$\mathrm{T}$ he Teaching Research Methods Track at the third annual APSA Teaching and Learning Conference included 26 participants from schools ranging from small colleges to major research universities. The program included presentations on the state of the undergraduate research methods field, information literacy, and a variety of teaching innovations, culminating in a large group discussion where we agreed upon a common set of strengths, opportunities, and challenges to teaching research methods, as well as a set of recommendations for a future Conference track.

\section{State of the Research Methods Field}

Our session kicked off with the preliminary results of a survey on the content of undergraduate methods courses in political science departments. The investigators found significant variety in the topics covered in the methods courses, although most courses focused more on "methods" than the scope of the discipline, and more on quantitative rather than qualitative methods. They also found that the methods course is typically the teaching responsibility of one or two faculty members, even in relatively large departments. These findings formed the backdrop for later debates among the participants about what the ideal form of the methods course - or a set of methods courses-might be.

\section{Information Literacy}

Two presentations focused on developing students' information literacy skills. Their approaches were tied to the standards of information literacy promulgated by the Association of College and Research Libraries and past research on students' progression in research and analytical skills. These papers emphasized the importance of developing student skills in locating relevant sources for research papers and of assessing whether the anticipated learning outcomes in these courses were met. As was the case for the research on the content of the methods course, these papers led to participant debate over whether these skills needed to be emphasized in the methods course or throughout departmental curricula.

\section{Teaching Innovations}

Not unlike presentations from previous years, many of the presentations focused on the problems inherent in teaching undergraduate research methods. Students lack basic knowledge of the research process and, more commonly, lack interest in research methods. The teaching innovation presentations focused on the various styles used to overcome these intrinsic problems.

A common theme was the importance of engaging student interest in research methods. Several suggestions were proposed, but the most common method used to engage students is to simply present them with behavioral phenomena they find interesting, and the more practical the material, the more engaged the students become. By using real-world examples that students can relate to through provocative readings and guest lecturers with policy implications, the presenters argue that student interest can be primed for further training.

Once the students are engaged the next step is to train students to understand what type of data they need and how they are going to analyze them. Teaching innovation presentations ranged from "Just Plain Data Analysis" (JPDA), the compilation and presentation of numerical evidence to support arguments at a very rudimentary level, to much more complex mathematical presentations directed at understanding formal modeling.

A discussion about what should be taught in an undergraduate research methods course brought the session full circle. There was general consensus about basic course content: an understanding of key political science indicators; where to find literature and supporting data; how to assess literature and the supporting data's academic quality; reliability and validity; the use of appropriate statistical measures; and data presentation skills. The group then discussed the best approaches for conveying the material, which varied greatly from faculty-lead, hands-on student-conducted research projects to online Internet-based hybrid-type courses to interactive techniques for teaching abstract concepts.

The importance of research methods as a required course was again discussed, a carry-over from last year's track. We agreed that research methods should be required and the students should be exposed to methods early in their academic careers so they will be better prepared to understand academic literature in upper-division courses. One solution is to integrate methods concepts across the curriculum using various lower-division courses to explicate the scientific method or particular methodologies. Integration of methods across political science courses may provide some remedy to the quality and quantity of methods training undergraduates receive.

\section{Conclusion}

By the close of the Conference, we agreed upon a common set of strengths, opportunities, and challenges to teaching undergraduate research methods, as well as a set of recommendations for a future Conference track. Our common goal is to provide undergraduate political science students with a strong fundamental understanding of the research methods used in our field and the skills to apply these methods outside of the classroom. Finally, we closed with two recommendations for next year's Conference. First, we would like to see more paper proposals based on formal assessment of teaching research methods. There are many opportunities for innovation reflected in the approaches presented during the Conference. What is lacking is systematic assessment of the competing course designs and teaching techniques. Second, we would like to see a roundtable with research methods textbook authors to discuss the motivations behind certain inclusions, exclusions, and approaches in their books.

\section{Teaching with Technology I Track Summary}

\author{
-Donna Axel, \\ New Jersey City University \\ -Ruth M. Ediger, \\ Seattle Pacific University \\ -Izabela M. Kaczorowska, \\ University of Illinois at Chicago
}

$\mathrm{U}$ nderstanding the importance of using technological tools in teaching political science, the organizers of the APSA Teaching and Learning Conference dedicated two tracks to teaching with technology. Track I was moderated by Robert $\mathrm{H}$. Trudeau of Providence College.

The first session focused on utilizing technology in the classroom. Antonio Rappa of the National University of Singapore demonstrated the usefulness of Integrated Virtual Learning Environment 
(IVLE), a web-based technology, for political theory courses. Three main benefits emerged from his research: professors can track students' performance level and depth of participation more easily, students can participate at their own pace, and professor-student communication can transcend the traditional school hours. Bob Van Dyk of Pacific University, Oregon, introduced ways to instruct students about Geographic Information Systems (GIS), a graphic computer program that layers data to help students understand physical relationships. For example, students used GIS to consider public policy issues such as resource allocation and preservation by juxtaposing maps of the breeding grounds of the spotted owl with logging maps. Mark Tompkins of the University of South Carolina explored the usefulness of two different computerbased programs that help students understand the complexity of federal budgetary constraints and common property issues involved in public policy decision making. Ruth Ediger of Seattle Pacific University presented data on student perception that a computer-based geoquiz program which tested student knowledge of the location of the world's countries and capitals is superior to traditional memorization methods. The students also reported that they were more likely to study for geoquizzes because it was enjoyable.

The second session assessed technological tools used among political science scholars and teachers. Roger C. Lowery of the University of North Carolina at Wilmington introduced Student-response Systems (SRS), a student-polling technology much like a TV remote control, designed to record and maximize student participation particularly in large classes. With SRS professors can increase students' active participation, awareness of their colleagues' views, satisfaction, and attendance. Gregory D. Miller of William and Mary College addressed the valuable role of movies inside the classroom. Like Lowery, Miller cautioned against using technology for technology's sake. John H. Riley, Jr. of Kutztown University of Pennsylvania compared the effectiveness of PowerPoint for three academic levels of students: high-, middle-, and low-achieving. He found that although high- and low-achieving students' grades were virtually unaffected, the grades of the middle-level group were significantly higher. Davida J. Alperin of University of Wisconsin, River Falls, assessed the difference between teaching with and without the use of computers, concluding that student performance and final grades are unaffected by computer usage.

The final session highlighted effec- tive strategies for e-learning and online instruction. Francis Moran, III of New Jersey City University compared final grade results for the 2004-2005 calendar years in specific classes with sections offered both online and in the traditional classroom each with identical substance. His research showed that the online student grades were higher, suggesting that the online environment provides a forum for debates in which ideas are more fully developed; alternative views are more common in light of the virtual anonymity; writing skills improve more rapidly; and "quiet" students participate. Moran resolved the researcher's ethical dilemma of exposing one group of students to potentially beneficial technology while depriving the control group by allowing students to select whether to enroll in an online or in-class section. Chunmei Yoe of Southeastern Oklahoma State University (SOSU) considered the practical and pedagogical implications of teaching American Government both in class and online; she attempted to maintain structural similarities. Yoe was unable to reach many definitive conclusions regarding whether online courses are more accessible (affordable/convenient) and/or efficient since the data available to her included only SOSU students, and it was not possible to determine whether online courses were more accessible and/or efficient to non-SOSU students. Ulrich Gysel of the International Relations and Security Network (ISN) at the Swiss Federal Institute of Technology Zurich (ETHZ) presented a paper co-authored by Sean Costigan of ISN/ETHZ. They introduced ways to utilize open source and cutting edge technology in serving cooperative security. ISN/ETHZ produces free, open material (www.isn.ethz.ch/edu) for teaching IR. To get a handle on openly available content, web-wide, they suggested establishing an e-learning in IR certification body and the possibility of a clearinghouse for open source e-learning content. The paper was presented with a mind mapping tool (http: //en.wikipedia.org/wiki/Mindmap) as an alternative to PowerPoint, which allows for presentations of ideas in a linear and non-linear manner.

\section{Lessons Learned/Conclusions Reached}

On the final day of the conference, the Teaching with Technology I Track summarized their sessions into a "Top Ten List of Conclusions" for the poster presentation. This order is only meant to imply that the final (or number one) conclusion is the most crucial:

10) For technology to be useful one should not be required to be a tech- nology expert; indeed many session participants were not technologically savvy, yet reported successfully using a variety of classroom technologies.

9) Although technology is a good tool to increase student enthusiasm, one could end up pandering to students and defeat potential learning opportunities.

8) Technology is beneficial for providing information as long as the temptation to overload students is avoided.

7) Institutional objectives are helpful in reducing the cost of education in some cases and in aiding standardization but could potentially get in the way of faculty goals. This problem can be avoided if institutional objectives and faculty goals are more deliberately harmonized.

6) When creating online courses it is important to consider whether the subject-matter is appropriate for the online setting.

5) Faculty, universities, and publishers all have a potential interest in the creation, ownership, licensure, and copyright of content and technology.

4) When conducting research on the effectiveness of technology for student learning, one must consider the ethics as well as ways to minimize the impact of measuring the effect.

3) The costs (time and money) to faculty and students involved in mastering and using the technology must to be considered. It is important to incorporate the technology in ways that students will not perceive as burdensome.

2) One must first establish clear teaching and learning objectives and goals and then decide if the technology is appropriate.

1) The primary focus of the teaching faculty is teaching and not technology. Technology can be used effectively to enhance student learning but it is not a substitute for good teaching. 


\section{Teaching with Technology II Track Summary: How and Why We Use Technology}

\author{
-Lela Long, \\ Troy University \\ — Joseph Vorbach, \\ U.S. Coast Guard Academy \\ -M. Victoria Perez-Rios, \\ The Graduate Center, CUNY
}

B lended learning describes the integration of computer-assisted teaching techniques with traditional approaches. Participants in the Teaching and Technology II Track considered several technology-driven means that contribute to effective learning to uncover a provocative array of blending processes. Presentations and discussion revolved around a variety of factors brought together by technology: traditional and modern views on technology and society, blogging and customary writing assignments, tech-savvy and conventional faculty, and multi-national faculty and students in a single classroom. Participants left the conference invigorated by the demonstrated possibilities, mindful of the challenges posed by cost and tradition, and focused on the successful use of technology to deliver the desired end-more effective teaching.

\section{Summary of Presentations}

Pamela Katz developed a web site to increase understanding of the state court role in the legal system. Cases which include summaries, learning activities, and webcasts for a comprehensive learning experience are linked topically from New York state courts to the U.S. Supreme Court. The model is applicable to other states due to its procedural focus.

M. Victoria Pérez-Ríos constructed a guided bulletin board-based tutorial that teaches U.S. Constitution basics to freshmen via active learning. Each step combines mutually reinforcing lectures with exercises. Students discuss their findings in class and online.

Brett S. Sharp uses iPods to study politics in music. Students download and play songs such as those used for campaigns and those based on civil rights, anti-war, and environmental movements while viewing the projected lyrics. Advantages are high student participation, a feeling of political efficacy, and a vivid lasting impression.

José Angel Gutiérrez and Joshua Been use census data and GIS software to help students understand the political implications of Latino voting power growth in Texas counties. Students use maps and tables to project trends and study relation- ships between demographics and voting.

Bruce Pencek developed a media based program to cultivate student information literacy. Students analyze unfiltered audio and video broadcasts to determine source credibility. The audio visual element is supplemented with readings, activities, and outlines.

Robert H. Webking drew on Plato's Republic to explore the primacy of images in knowledge obtainment. Technology by its conveyance of pictures, data, and other simulations can help students move from understanding objects to concepts. Much discussion ensued as the presentation is at the crux of the debate over technology as instruction or entertainment.

Gerald M. DiGiusto used blogging to enhance conventional world politics instruction. Additionally, the merits of individual student blogs are contrasted with a group blog. The latter was more manageable as DiGuisto did not have to check a number of separate web pages. Advantages of blogs were high participation and peer-to-peer and student-professor-interaction.

Tomas Karasek and Anja Hennig developed a tri-national course (Czech Republic, Germany, and Poland) in comparative foreign policy integrating online modules with face-to-face workshops. Students were divided into multinational groups to enhance the cross-cultural aspect; they acquired empirical knowledge, social skills across cultures, and multimedia competency.

Richard Vengroff and James Robert Bourbeau compared traditional, online, and hybrid versions of a comparative politics course. The hybrid course had higher student satisfaction and participation than the other two with the notation that the hybrid course was composed of honors students and the online component was in addition to regular class hours. Participation was higher in the strictly online class than in the traditional class, but student satisfaction was slightly higher in the traditional class than in the online class. Grades were similar across all three.

Rosa Gomez Dierks promoted the need for technology leaders, cooperation teams or e-communities, and mentor-apprentice dyads to share, sustain, and increase technological knowledge in academia. The Teaching and Learning Conference is a bright step forward.

Joachim Karl Rennstich advocated methods to incorporate global voices into the classroom. Cell phones, laptops, and webcams can provide historically inaccessible information to students and foster research collaboration among diverse communities.
Conclusions and Future Steps

The Technology II Track broke new ground regarding the use and assessment of technology and reiterated obstacles expounded upon last year. Technology enables student interaction with information in accessible, immediate, and familiar formats, increasing classroom preparedness and discussion. It enhances and extends the learning process, while the academic mediates learning and guides students through the labyrinth of available information and tools.

The use of technology has costs. First, it may distract from the core objective of learning, especially upon occasions when it fails or is used as a crutch. Second, implementation requires time and resources; these commitments may decrease over time as familiarity and aptitude increase. Finally, as technology brings some students into the classroom, it leaves out others.

Additional steps are needed to advance the use of technology and determine its role in the political science classroom. Practically, copyright issues must be clarified, and a forum is needed to archive proven technologies and provide peer review for emerging uses. APSA may be the ideal organization to undertake this role. Pedagogically, there must be an assessment of specific technologies to achieve discrete objectives and a determination of whether technological skill is a legitimate goal for political science departments. Track participants agreed that technological skills can help provide quality courses and prepare students for a technology driven world. However, they must be systematic and discipline directed.

\section{Assessment/Learning Outcomes I Track Summary}

\author{
—John Berg, \\ Suffolk University \\ -Kerstin Hamann, \\ University of Central Florida \\ -Dianne Long, \\ California Polytechnic State University
}

ssessment is of increasing impor-

A tance for political science faculty and departments across the discipline. One indicator of this relevance is the diversity of backgrounds of the 24 presenters and participants in our track, ranging from graduate students to full professors and deans, housed in institutions of higher learning ranging from community colleges to Ivy League universities, and 
belonging to departments ranging in size from 40 majors to over 1,100 . Some attended because they wanted to share their enthusiasm for assessment, while others were interested in learning more about a process they were forced into by administrators, legislatures, or accreditation agencies. The group discussed many different aspects of assessment, including designing measurements for classroom and program assessment as well as some of the problems linked to assessment. We proposed the following summary conclusions:

\section{Assessment is an integral part of teaching and learning.}

Assessment focuses on finding out what students have learned. While not all departments and faculty members may value imposed assessment activities, most can agree that measuring student learning is important. Politicians, accreditation requirements, and university administrators put increasing value and weight on assessing what has been achieved and to determine the value of public and private investment in education. Consequently, more college and university faculty are taking a proactive approach to assure that the discipline will identify what is important to assess and what measures and practices are most useful in defining student achievement. Assessment allows faculty to verify what students learn; consequently, it will facilitate informed decisions about curricula and programs.

\section{Learning objectives are the building blocks of assessment activ- ity. \\ Before assessment can take place, it is} critical to set out the learning objectives for the particular courses and groupings of courses. These objectives are best stated in terms of learner objectives, such as increase in knowledge or skills. Assessment links learning objectives with learning outcomes to see whether students have acquired the skills and knowledge they are taught. This is true for classroom and program assessment alike, and both levels of assessment are closely linked: We teach programmatic objectives through our courses and, often, we use course work to measure the extent to which students have achieved programmatic goals.

\section{Political scientists have the skills to conduct meaningful assessment.}

The political science quantitative and qualitative toolbox includes case studies, scoring rubrics, surveys, content analyses of portfolios, rating scales, reflective essays, standardized achievement tests, and focus groups. This toolbox fully equips faculty in the discipline to conduct meaningful assessment that can demonstrate the value of the discipline as part of students' educational experience.

\section{Assessment can be beneficial.}

By analyzing what the students have and have not learned, instructors and programs can improve curricula and teaching methods, thereby improving students' learning. Since program assessment is a collaborative undertaking, the endeavor can stimulate new conversations and partnerships among departmental faculty members and with other units on campus, such as assessment or teaching and learning centers. Assessment results can be used to demonstrate the unique contribution our discipline makes for higher education. They might also be used to leverage additional resources for political science departments and faculty. For individual faculty members, assessment provides another opportunity to engage in research by practicing the scholarship of teaching and learning.

\section{Assessment is not without challenges.}

The assessment process requires resources and time, and often these are not readily available. Moreover, oftentimes faculty members find it difficult to agree on what is to be assessed, and how. If assessment produces improved student learning, that ought rightly to lead to higher student grades - and to the perception of grade inflation. In addition, faculty members often fear a general loss of autonomy, particularly if assessment is imposed from the outside. Finally there is the Big Fear: What if we measure student learning and find that there is none? Will we lose students, administrative support, and funding as a result? And what of the individual faculty whose courses are found to be ineffective? Will they suffer punitive consequences? Given these fears, departments may be tempted to devise assessment measures that are designed to cover up problems, rather than reveal them. If assessment is to be effective, it must not be punitive-but that principle may be hard to maintain in practice.

\section{Next steps.}

Our track members concluded that assessment is becoming a part of the academic endeavor that will gain in importance. Consequently, the track suggests that APSA continue to facilitate and take a more visible leadership role in assisting faculty members in their assessment efforts, both at the level of classroom instruction as well as at the programmatic level. APSA could become more engaged in the national discussion on assessment, help develop testing instruments that are germane to the discipline and could be obtained at low cost to faculty and departments, and take a leadership role in coordinating resources and training for assessment in the profession. It is essential that assessment demonstrate the unique contribution political science makes to the undergraduate curriculum. Despite the problems inherent in assessment, it is thus of fundamental importance to the discipline.

\section{Assessment/Learning Outcomes II Track Summary}

\author{
-Paul Edleman, \\ Sauk Valley Community College \\ - Jocelyn Evans, \\ University of West Florida \\ - Halima Khan, \\ Northern Illinois University \\ -Jessica Schattschneider, \\ Freie Universität Berlin \\ -Michelle Hale Williams, \\ University of West Florida
}

$\mathrm{A}_{\text {and Learning Conference, attendees }}^{\mathrm{t} \text { the third annual APSA Teaching }}$ in the Assessment/Learning Outcomes II session engaged in vigorous discussion over how best to integrate assessment with learning. The participants reflected a good mix of both community college and university perspectives, yet found that the necessity for efficacious assessment cuts across the discipline; concerted efforts should be made to encourage and enhance learning and consequently, assessment. Key themes that emerged from the track are reviewed below.

\section{Fostering a Measurable Assessment Culture}

Conference participants acknowledged the challenges of fostering a measurable assessment culture within the political science discipline. A recurring idea was that if political science does not govern its own discipline with respect to assessment, someone else would. To this end, APSA should take the lead in providing resources to departments and faculty interested in developing assessment programs. Some of these resources may include an APSA web site where members can access examples of "best" and "worst" practices posted by other members, sample department programs' missions and learning objectives, and utilize a test question databank. Assessment need not be difficult or threatening. In most instances, it can be 
embedded within the larger teaching and learning context and actually reinforce active learning pedagogy. In fact, many of us already perform assessment without recognizing it as such. It is often simply a matter of documenting what we are doing in the classroom and in the department, and then using the information to provide feedback. At the classroom level, closing the feedback loop can help improve classroom teaching and evaluate the usefulness of new experimental learning techniques. At the department level, assessment can be used in the program review process to advocate for the purchase of new equipment, justify the hiring of additional faculty, or increase department funding.

\section{Recognizing What We Don't Know in Political Science}

The presentations to the working group covered a wide range of topics from study abroad to information literacy education. In the end, however, all of them raised similar questions, which resulted in the recognition of three basic problems. First, we have no empirical knowledge about the impact of factors such as gender, GPA, and class ranking on the learning process. Second-and most discussed-is the question of what makes a meaningful assessment that is specific to political science, which not only focuses on knowledge but on skills and literacy-and all this without running the risk of repeating the mistakes implemented in $\mathrm{K}-12$. As in previous years, devising an effective way to evaluate critical thinking headed the list of priorities, followed by the measurement of civic participation. Third, the majority of participants perceived that when becoming acquainted with assessment, it seems as if we are re-inventing the wheel, rather than crossing the Rubicon. There was an agreed desire for the discipline to discover a way of gathering and sharing national data on assessment and evaluation in political science.

\section{Measuring Political Participation/ Active Citizenship}

With the shift toward learning outcomes across academia, political science has positioned itself as the discipline that best cultivates political participation. However, active citizenship has proven challenging to assess. Our track discussed several possibilities for better assessment. Understanding information emerged as a precursor to active citizenship; we discussed how students must be able to determine the nature of information needed, to collect, sort, and analyze information, and to apply information to a particular task. Political science and library faculty suggested information literacy education as a tool. As active citizens, students must think critically. To do so they must make applications and reason logically toward analysis; measures of recall do not capture these skills. We discussed the importance of active learning assignments. Student context appears to holistically affect the way that students choose to engage, so we collectively began to refer to it as the "ecosystem." One presentation highlighted survey results showing that contemporary students engage in new forms of activism. These include wearing a yellow wristband, blogging, signing online petitions, text messaging poll responses, and boycotting a company. We wondered whether active citizens today "bowl alone" rather than together. Students appear to have a sense of efficacy through such actions and future studies of active citizenship may need to consider including them in analysis.

\section{Future Areas of Research}

One of the major themes to emerge concerned future areas of research. We, as a discipline, would benefit from better theory, better data, and more comparative research on assessment. At its core, assessment lacks a clear theoretical framework. We should think through the broader purposes of assessment as well as the specific ways in which assessment can be used to facilitate better teaching. While individual teacher-scholars are conducting excellent classroom experiments to improve personal and institutional assessment instruments, participants noted the need for collaborative datacollection across institutions as well as across disciplines. APSA might consider hosting assessment-related data available for public use. In addition, a major consensus of those in Assessment Track II was that there is a need to compare assessment tools as well as outcomes across various institutional settings, various levels of political science education, and various modes of instruction. By comparing assessment across public and private institutions, graduate and undergraduate courses, distance learning and traditional classroom settings, study abroad and on-campus environments, and elective and required course settings, we can more accurately identify what educational opportunities lead to what educational outcomes.

\section{Conclusions}

As can be evidenced from the preceding discussion, two pressing issues come to the fore: How best to integrate learning and assessment, and what should be the role of the APSA in the area of assessment? Every participant felt an obligation to enhance students' learning so that the educators can better equip them with critical thinking skills that can be transported across disciplines. An oft-repeated criticism of the field is that political science is theory without context; both presenters and discussants felt a need to mesh the two so that students can grasp the material being taught and that educators wield a tool to measure such learning. Another area of discussion was whether contemporary standards should be assimilated in learning and assessment to spark the interests of the students. As mentioned earlier, activism among students is of a different nature than activism of earlier generations. The fact that paucity in knowledge assessment has been noticed and efforts are being made to address the issue gives tremendous hope to those passionate about teaching.

\section{Assessment/Learning Outcomes III Track Summary}

\author{
-Lisa A. Cave, \\ Morehead State University \\ -Allison M. Johnson, \\ University of Nevada, Las Vegas \\ -S. J. Lange, \\ Morehead State University \\ -Lindsey Lupo, \\ University of California, Irvine
}

A ssessment, by definition, is a means of estimating the quality or value of something. In this case assessment may be geared toward students directly in the form of enhancing learning, faculty in terms of better teaching, departments for improved curriculum development, and institutions for the purpose of public relations, resource allocation, and accreditation. This panel examined assessment in all of these cases, with a particular focus on assessment of learning outcomes. Learning outcomes are at the very essence of what we as teachers are trying to achieve and assessment provides us with ways to determine whether we are actually meeting these goals. The purpose of this track was to examine both assessment and learning outcomes and to develop ways to improve both. This article synthesizes the main findings of papers presented in the track together with the ensuing discussion. The article is split into five major topics: the role of assessment, the uses of assessment, the inevitability of assessment, approaches of assessment, and how we do assessment. 


\section{The Role of Assessment}

First, what are we assessing and why? The panel agreed that at root we are concerned with assessing student learning. Consequently, assessment should be used as a tool in the pursuit of providing a clear understanding and enhancement of student learning. To answer the question's second part, why we assess student learning, we must first determine what we ultimately want students to learn in political science. Thus, the first goal of assessment must be to develop a clear outline of the specific skills, values, and knowledge content (significant learning) that we want students to obtain from individual classes and from the political science curriculum as a whole. This will provide criteria that will allow us to determine whether students are learning.

\section{The Uses of Assessment}

Should assessment be viewed as a goal or as a tool? Administrators may be predisposed to consider assessment as a goal due to institutional and legislative pressures to compare programs and institutions. Faculty members tend to resist assessment when it is used for this purpose. Conversely, faculty view assessment as a means to the ultimate end-the enhancement of student learning. Specifically, faculty regard assessment as a tool and learning as the goal. The panel established that assessment should be used to determine student learning outcomes, discover teaching strengths and deficiencies, and make curriculum changes, with the ultimate goal of increasing student learning opportunities. While assessment may take many different forms, and there may be many different uses, all of these goals should converge to enhance student learning.

\section{The Inevitability of Assessment \\ Increasingly assessment is being} forced upon faculty by administrators and legislators. As faculty members we must use this opportunity to shape the assessment process. Fundamentally, we should take charge of assessment. There must be a concerted effort to examine how other disciplines that have developed proficient assessment techniques, such as sociology and nursing, use assessment, and then employ those methods that best underscore the purposes that matter most, enhanced student learning. It was suggested that the APSA create a clearinghouse of tools for assessment on its web site with links to other competent assessment programs (e.g., nursing, psychology, and sociology), develop a task force on assessment, hold workshops at regional meetings, and include panels on the politics of assess- ment at the next Teaching and Learning Conference.

\section{Approaches to Assessment}

There are several different approaches to assessment. In particular, the panel outlined three characteristics of assessment: assessment of learning, for learning, and as learning (Earl 2003). Assessment of learning uses traditional assessment techniques, such as exams, papers, and tests, to determine what students are currently learning in their classes. Assessment of learning is summative in nature. Assessment for learning, a formative approach to assessment, observes what students are learning and where there are deficiencies on an on-going basis. This characteristic of assessment employs such techniques as students submitting a note card each week with questions that they may have. The final characteristic of assessment, assessment as learning, uses different assessment techniques, such as having students write self-reflection papers, their own political autobiographies, peer reviews, and engaging student participation as a means to encourage civic engagement.

\section{How We Do Assessment}

The overarching point that resulted from this discussion was that assessment requires multiple tools, and that the tools themselves must be flexible. Standardized assessment tools, such as IDEA forms, retention rates, GPAs, and GRE scores, are popular with administrators and legislators as they facilitate a comparison of institutions and allow for national rankings. In contrast, faculty members are typically opposed to student and faculty assessment on the basis of solely standardized means. Using only standardized assessment measures pressures faculty members to "teach to the test" in order to improve department or institutional standings. This contravenes the purpose of higher education and academic freedom, and it does not allow for assessment of educational experiences that are difficult to test from a standardized perspective, such as internships and study abroad programs. While some amount of standardized testing is inevitable, faculty, departments, and administrators must be diligent in developing and employing other forms of assessment, such as entrance and exit interviews, alumni surveys, and intern debriefings, to be used in conjunction with standardized tests.

The purpose of the session was to investigate assessment and learning outcomes. Through the course of presentations and discussion we tackled this issue and explored new approaches to assess- ment that show the importance of having clearly outlined course goals and the use of assessment as a means to an end rather than an end in itself. Further discussion analyzed the different uses of assessment, of learning, for learning, and as learning, which evolved to include the different approaches for which assessment may be used. Although faculty may be resistant to standardized assessment, it is inevitable. Therefore it is in our best interest to find multiple, flexible methods of assessment to be used in conjunction with standardized means to meet our ultimate goal-enhanced student learning outcomes.

\section{Reference}

Earl, Lorna M. 2003. Assessment as Learning: Using Classroom Assessment to Maximize Student Learning. Thousand Oaks, CA: Corwin Press.

\section{Simulations and Role Playing (S\&RP) I Track Summary}

\author{
-Amy Lovecraft, \\ University of Alaska, Fairbanks \\ -Wesley D. Chapin, \\ University of Wisconsin, River Falls \\ —David C. W. Parker, \\ Indiana University, South Bend \\ -David Sadler, \\ University of Northampton
}

\section{Purpose of S\&RP}

Undergraduates often have difficulty conceptualizing phenomena for which they have little experience, such as life in an Islamic state or the pressures of foreign policy decision making. The participants of the S\&RP Track I explored multiple ways political science might address this challenge. While the exercises employed by participants differed, the desire to help students experientially learn key concepts and materials provided the central motivation. S\&RP are a valuable complement to traditional teacher-centered methods of content delivery, such as lectures that tend to focus on acquisition of knowledge without reflection. One clear advantage of $\mathrm{S} \& \mathrm{RP}$ is the ability to encourage synthesis and evaluation of information by literally taking students out of their chairs and having them "learn by doing." Such strategies help students shift their roles from being passive receivers of information to active participants in the learning process. The participants of this track felt strongly that S\&RP can play a vital role for students, faculty, and their institutions by enhanc- 
ing faculty ability to impart key skills, analytical tools, and varied perspectives to students who in turn become empowered as a part of their own education. As institutions compete for students and students demand applicable courses, novel teaching methods that make clear connections between political instruction and the lived realities of those taught benefit everyone.

\section{Design Elements of Simulations and Role Playing}

Although rewarding for participants and instructors, the creation and execution of a successful S\&RP activity can be time-consuming and challenging. Instructors must consider that even well-designed plans can fall victim to unforeseen circumstances, such as when participants fail to play key roles properly or technology-based simulations have glitches. Careful attention to the pedagogical goals of the simulation, time for preparation and debriefing, exercise format, and appropriate assessment increase the chances of significant student learning despite occasional unanticipated variables.

Numerous, usually overlapping, goals might be pursued in a simulation but knowing one's goals in advance is critical. For example, Wesley Chapin's Futura exercise prompts student teams to design governments, promoting student coordination and decision-making. Evaluating concepts of fairness in the absence of a classroom clique or social cues is a goal of Amy Lauren Lovecraft's tax experiment. In both cases, each activity helps students better understand and appreciate the problems of collective action through shared engagement. Instructors also may want to enhance specific course content or key skills. The Moot Court, as presented by John Kearnes and Becky daCruz, focuses students on honing the argumentation and textual analysis skills employed by lawyers, and the course design of Victoria Williams and Daniel Lang uses classic texts to teach modern political skills. Another common theme among the presentations was the connection between the theories of politics and their practice. Chapin's project of creating states from scratch, Michael Alan Brittingham's simulation of international tension over Taiwan, David Sadler's recreation of the Cuban missile crisis, and Brian Cook and Kristen Williams' presidential crisis all allow students to experience the pressures and pitfalls of Realpolitik. Lastly, experiential learning events can enhance student understanding of "the other." How can students living in a democratic society understand the everyday realities and pressures facing citizens living in a totalitarian state? By having students assume legal roles in an Iranian court, Janet Laible encouraged students to learn the difficulties facing citizens engaged in a polity very different from the United States. In each case, students acquired new tools to both analyze and participate in political scenarios.

Once the goals have been established, instructors must consider some key variables as they design their S\&RP tools. Course enrollment, the availability of technology, time constraints, the nature of the material, the degree of control an instructor desires, the level of complexity, and the preparation time needed are pertinent considerations for exercise design. Furthermore, the results of each simulation will be unique and debriefing is critical to student contextualization of their experience. The value of the simulation itself may not even be apparent to some students until they reflect upon it orally, in writing, or both. How one assesses the significance of the exercise can be crucial to demonstrating the worth of simulated learning to colleagues within and outside home departments and to administrators. Ideally, assessments should be both quantitative and qualitative. In any case, keeping good records of an S\&RP exercise and creating a feedback mechanism from students are keys to avoiding problems and refining the simulation for future use.

\section{Current Challenges and Future Directions}

Using S\&RP exercises in class is not without its challenges. For extensive projects, institutional support can be important to reduce costs or coordinate student availability. Even in small-scale exercises other problems may arise, such as the free rider. Most instructors supplement careful monitoring with peer evaluation to ensure the widespread and meaningful participation of students. Sometimes difficult to overcome is the tendency for assigned roles to become stereotypes. For example, students who assume controversial identities, such as portraying Fidel Castro, are likely to need more guidance than a student in a role more closely related to her or his interests. The most complex simulation roles require careful student preparation to ensure not only accurate portrayal, but avoidance of issues related to ill-prepared or absent students; both can wreak havoc with the success of role-playing exercises.

The investment costs of S\&RP exercises in terms of time and energy are high for instructors, but the rewards can be substantial. Students enjoy simulations, achieve "deep learning," and remember the event long after taking the class. In many instances, students reward instruc- tors with better teaching evaluations, perhaps as a function of the degree of learning they achieved in the course. Furthermore, as the academy embraces more forms of cross-disciplinary methods and courses, simulations are well suited to help students bridge fields of knowledge. As in real life, simulations require of students a mixture of skills such as effective communication, strategic thinking, considering history, or handling budgets to address any particular political problem. Unfortunately, many would-be converts are discouraged by the investment costs necessary for S\&RP success. This is indeed a daunting hurdle to overcome with the increasing expectations placed on faculty. To encourage others a network should be created where simulation-users can share their experiences, ideas, and designs. Many instructors create and use simulations in isolation, yet the S\&RP Track I discussed the similarity of instructor experiences across and beyond the United States. It is time to make experiential learning a collective enterprise, and the development of such a network through APSA and its linkage to other networks such as those in the UK is strongly encouraged.

\section{Simulations and Role Playing (S\&RP) II Track Summary}

\author{
—Thomas C. Ellington, \\ Wesleyan College \\ - Michael Grillo, \\ University of Delaware \\ - Carolyn Shaw, \\ Wichita State University
}

$\mathrm{P}$ articipants in this track were delighted to see a number of common themes develop during our presentations and discussions throughout the conference. Participants included faculty and graduate students from a variety of subfields who design creative exercises to actively engage their students in learning. With the wide range of simulations that already exist and the growing body of literature addressing the design of new simulations, faculty have significant resources at their disposal to incorporate simulations into their courses. Simulations are so readily adaptable they can accommodate almost any course content or learning objective.

\section{Benefits for Students and Faculty}

While the participants in the track had differing opinions and concerns about how simulations should be designed and 
implemented within the classroom, there was unanimous agreement that the use of such pedagogical methods are extremely beneficial for both students and faculty. In terms of student learning and development, there were several common themes consistent through all of the presentations and subsequent discussions:

- Simulations enable students to apply the content of courses into real life situations. This provides students with a much deeper understanding of differing perspectives, which is particularly important for students who might not have experienced much outside of their own hometowns or geographical regions.

- Simulation learning enhances students' research, writing, analytical, and critical thinking skills.

- Simulation learning fosters a greater sense of student ownership and responsibility in the classroom. This has been shown to increase student's civic engagement beyond the classroom. Additionally, simulation learning can create links between courses that can facilitate campus-wide learning, which is the essence of a liberal education.

- Simulations make learning more exciting and fun by actively engaging and including students in the educational process. This can, in turn, increase their motivation to learn and actively participate. Furthermore, simulation learning provides students with a memorable experience that they can take with them beyond the classroom, whether they decide to enter the work force or pursue graduate studies.

Benefits to faculty members include:

- Use of simulations help instructors better engage and connect with their students, which makes the teaching process more fulfilling and exciting. This is especially important for faculty who teach the same classes regularly, as it provides them with a way to keep things fresh and exciting.

- Simulations provide faculty with clear feedback on teaching effectiveness. They can provide a greater sense of how well students are learning and retaining the material in a way that they can practically use, as opposed to simple memorization, which is easily forgotten after the exam or when the semester has concluded. Moreover, such feedback can also assist faculty in modifying their teaching methods to optimize student learning.

- The use of simulations provides a way for junior faculty and newly minted Ph.D.'s entering the profession to demonstrate teaching innovation and mastery, which for many universities is just as important as researching. The effective use of such cutting-edge pedagogical techniques has professional benefits in helping junior faculty obtain tenure.

\section{A Shoe for Every Foot: Design Con- siderations for Simulations}

Simulations are used across the discipline in a variety of classes including American government, international relations, political theory, and comparative politics, with time commitments ranging from a single class period to a full semester. Simulations, however, are not "one-size-fits-all." Finding a simulation that fits the learning objectives of your course requires consideration of a variety of factors:

- Know your comfort level. Simulations do involve giving up some control of the classroom to students. Any instructor running a simulation for the first time ought to begin with a simple exercise rather than a semester-long commitment.

- Know your student population. Relevant variables to consider include class size, students' background, and whether your course is an introductory or upper-division course.

- Know your own goals. Your design should be driven by what you hope to accomplish. If you are seeking to illustrate one or two concepts and offer students a common concrete experience upon which to reflect, your design will look quite different than if you are seeking to have your students develop sophisticated skills through extensive hands-on experience.

- Know your institution. A more supportive institutional environment provides for more flexibility for incorporating innovative teaching techniques.

- Have realistic expectations. It is important not to underestimate the time commitment or other costs you may incur in running a simulation. With a good design, these costs are more than exceeded by the benefits, but you can make that judgment only if your expectations. And be flexible. By their very nature, simulations are frequently unpredictable. This is a virtue. Unexpected events often hold a great deal of educational potential.

- Consider how much advance preparation your students will need. In some cases, a five-minute instructional briefing may be all that is necessary. For more sophisticated designs, students may need a great deal of instruction on playing their roles or using technology.

- Communicate clearly with students about expectations and grades. Let students know that there is more to the exercise than simply "playing a game." Students are more likely to take the simulation seriously if they understand what they are expected to do and how they will be graded. Formal grading may be unnecessary for a single-classsession game, but longer simulations should have graded components. Popular methods include reflection essays and evaluating the quality of role playing. Many simulations involve the production of documents such as briefs or proposals, which are readily evaluated for quality.

- Consider the resources available to you. These resources may include technology, teaching assistants, outside experts, and other academic or simulation-design materials. Many simulations also offer opportunities for student leadership either in the actual roles or in administration of the activities.

- Consider how realistic you want your scenario to be. Hypothetical or fictional scenarios can be less messy and help students focus on the major principles or concepts without distraction. However, scenarios drawn directly from real-life may be more engaging.

- Plan on a debriefing period. Students frequently need a chance to articulate their feelings about the simulation experience. This is a critical time for helping students to link concepts with their experiences.

- Plan on and build in assessment. If an argument for simulations is that they aid student learning, it is helpful to be able to demonstrate that they accomplish their goals. A well-designed assessment can also be useful as a diagnostic tool for further refining of a simulation design. 


\section{Community-based Learning I Track Summary}

\author{
—Elizabeth Bennion, \\ Indiana University, South Bend \\ -Patrick McKinlay, \\ Morningside College \\ -Holley Tankersley, \\ University of Georgia
}

$\mathrm{C}$ ommunity-based learning (CBL) reflects the principle that political science courses should do more than simply teach students about politics. As participants in the community-based learning track, we believe that courses in our discipline should equip students with the combination of knowledge, skills, and values required to engage in a life of active citizenship. Designing a course that meets these goals is not impossible. Communitybased projects include several different types of experiential learning, including: service-learning, community-based learning, and community-based research. We believe that all of these forms of learning about, from, and with the community inspire and encourage students to live an active political life.

CBL also provides an opportunity to close the gap between teaching and learning by moving away from memorization toward analysis and application. Educational research makes it clear that many college courses fail to challenge students' preconceived world views in ways that leads to deep learning (Bain 2004).

Through CBL, students are exposed to a diversity of people, places, and social circumstances; such experiences serve to challenge preconceived notions about groups and individuals in society. The dynamic application of course concepts in a "real-world" setting encourages active citizenship while combating apathy, and may also help students to develop valuable interpersonal and vocational skills.

\section{Putting the " $L$ " in Community-based Learning}

Community-based learning projects must be integral to course design. Ironically, many of the goals of communitybased learning are reached in the classroom. It may be difficult for students to conceptualize what they are seeing and doing in the moment of service; however, when given a framework within which they can explore and reflect upon their activities, students make critical causal linkages. There are several ways to link community-based service and research with course content, including: assigned texts, classroom discussion, classroom simula- tion, and structured reflection. Promoting learning outcomes in a structured manner is vital to distinguishing community-based learning from simple volunteerism.

\section{Taking it to the Streets}

Community-based learning course designs require substantial prior planning to work with university and community partners to conduct proper needs assessment. Aligning course content with community-based projects is a necessary, but not sufficient, condition for successfully meeting community-based learning goals. Track participants stressed the importance of building strong community relationships with individuals, groups, and agencies. Some communities may perceive community-based learning projects to be paternalistic and patronizing, or at least out of touch with problems outside of the ivory tower. There are strategies to mitigate this distrust. Students should "do what needs doing," rather than making assumptions about community needs. Faculty members can aid in this process by cultivating long-term relationships with local groups and agencies, as well as staying informed about local issues and problems. Once community relationships have been established, they must be maintained. Students should be reminded that they are making a significant commitment that requires them to show up and act professionally. Therefore, it is critical for all stakeholders involved to clarify their expectations of the project's implementation and outcome. It is also important to thank community partners, both informally and with formal awards or recognition.

Faculty members should leverage all available institutional resources to help build these key community relationships. Our track participants came from a wide variety of institutions with varying resources; some had the benefit of a full-time service learning center, while others tried to do everything themselves or relied on student assistants as leadership trainers. Track members agreed that institutional support is critical to a successful CBL project. Teaching and learning centers, service learning centers, student unions, work-study programs, and government-funded positions (i.e., VISTA) are all useful resources for campus-based CBL programs. It is also important to integrate $\mathrm{CBL}$ into the institutional mission and curriculum.

\section{The Payoff: Assessing the Impact of $C B L$}

Although we are convinced that community-based learning is an important pedagogical tool, your institution's administrators, faculty members, students, and alumni may demand concrete evidence. Track participants used different methods for assessing both short- and long-term learning and attitudinal outcomes. Preand post-class surveys and interviews, content analysis of students' written reflections or classroom comments, and focus groups are valuable tools for assessment, as are case studies of the individual experiences of students and community partners. Because community-based learning is designed with the end-goal of enhanced civic engagement and active citizenship, its effects may not be immediate. Longitudinal studies of alumni who participated in CBL courses and projects are useful for assessing long-term impacts. Another long-term assessment mechanism involves a college-wide entrance and exit survey that can be compared with national surveys about community service and civic engagement.

Track participants mentioned several benefits of impact assessment including enhanced opportunities for: evidencebased curricular reform, SoTL presentations and publications, grant money, and enhanced cooperation from university and community partners. As political scientists, track participants believe evidence supports CBL pedagogies as significant tools for "deep learning" of key disciplinary skills, methods, and concepts. As we show our students, our colleagues, and our neighbors the benefits of CBL, they will become stronger partners in promoting the ideals and values of active learning and active citizenship.

\section{Reference}

Bain, Ken. 2004. What the Best College Teachers Do. Cambridge: Harvard University Press.

\section{Community and Service- based Learning II Track Summary}

\author{
-Leanne Doherty, \\ Simmons College \\ -Suzan Harkness, \\ University of the District of Columbia \\ -Kendra King, \\ Oglethorpe University
}

diverse gathering of academics
lconvened to discuss Community and
Service-based Learning (CBSL). The
common bond amongst all was the belief
that developing tangible linkages with the 
community through myriad "service" instruments is critical in producing a holistic educational experience. Our common agreement was that CBSL programs must be well-structured, academically rigorous, and properly assessed and evaluated in order for students to obtain the most out of the experiences. The goal of CBSL II was to address these issues and discuss what does and does not work.

\section{The P3 Model-Planning, Planning, and More Planning}

In order for CBSL to be successful, planning is fundamental. The majority of the leg work (initial meetings with community leaders, internship liaisons, and host/internship sites) must be done before hand. Beyond the initial academic/ community and service-learning contact where the commitments and goals of the academic institution are established, early planning stages should also include identification of key players, establishing trust between the community/internship host site/service-learning organizers and the academic institution, and the completion of as much administrative paperwork as possible.

\section{CBSL II Typologies}

CBSL II participants shared numerous models and typologies that rigorously engaged students both inside and outside of the classroom (the overarching goal was to connect work outside of the classroom with solid academic principles espoused inside of the classroom). Leanne Doherty created a pilot internship program with a required writing infusion course to meet an institution's Writing Across the Curriculum agenda. Judithanne Scourfield McLauchlan used experiential learning to supplement her course on the Florida courts. Edward Warzala and Michael Stone utilized learning contracts as a means of combining the best aspects of community-based learning and the cognitive, affective, and behavior goals of higher education. David Redlawsk and Nora Wilson used a "job fair" model to introduce students to city council campaigns. Kendra King holds a semesterlong course on community building which convenes with a "summit" of community leaders, political officials, and university members as a means of connecting all sides. All papers underscored the need for a balance between service-based learning objectives and academic/discipline pedagogy.

\section{Methodology}

One of the fundamental themes (as well as intense discussions) emanating from CBSL II evolved around complimentary, competing, and seemingly contradictory pedagogical patterns. Our discussions revealed a variety of methodological tools used to track students' progress in their placements, including: guided journaling, writing reflections, field notes, portfolio building, group reflection, contracts, oversight, and feedback loops. Brigid Harrison and Quentin Kidd incorporated a long-term commitment model for their internship and intensive leadership program. Their model required students to complete both pre- and post-program civic engagement surveys. Margaret Post and Adam Reich discussed story telling as an effective community organizing tool for students involved in a variety of local level democratic processes. And Christine Pappas asked students to journal their experiences interacting with and "cleaning-up" a local community during a week-long project. Many of the pedagogical tools utilized in CBSL II were similar. Interestingly, in his paper detailing the transition from service learning to civic learning, Steven Jones presented a typol- ogy of successful methods of pedagogy that were nicely echoed and supported through other track participants' research and presentations.

\section{Assessment}

Our track unanimously agreed that layered assessment was essential to CBSL programs. These assessment methods included formative and summative assessments (pre- and post- program), stakeholder discussions, evaluations from and by different audiences, and assessments of students' knowledge, skills, and disposition. Participants emphasized layered assessments as important in order to satisfy several constituency bases, including donors, deans, department chairs, and students. Moreover, effective assessment(s) foster solid and meaningful relationships and partnerships with the communities the academic institutions seek to serve.

\section{Final Thoughts}

One general viewpoint expressed was the challenge of creating and carrying out CBSL projects. Participants were conscious of the viewpoint that stereotypes this type of learning as lacking scholarly rigor. Additional challenges to engaging in CBSL include: 1) balancing university and community interests; 2) assisting students in fulfilling multiple demands and responsibilities; and 3) faculty support (especially for untenured faculty) in incorporating CBSL into tenure and promotion.

In spite of these concerns, CBSL programs are ongoing, wide-ranging, and expanding. Undoubtedly, students, faculty, and community members have found value in learning outside the classroom. Whether the course leads to a life in politics, community service, or makes students conscientious voters, a successful learning experience has taken place. 